\title{
ANALISIS KONTRIBUSI KAWASAN EKONOMI KHUSUS (KEK) TERHADAP STRUKTUR PEREKONOMIAN SULAWESI UTARA
}

\author{
Victoria Natali Makalew, Vecky A.J. Masinambouw, Een N. Walewangko \\ Ekonomi Pembangunan - Fakultas Ekonomi dan Bisnis \\ Universitas Sam ratulangi
}

\begin{abstract}
ABSTRAK
Sektor industri dianggap mampu untuk mendongkrak sektor-sektor lainnya dalam meningkatkan pertumbuhan ekonomi suatu daerah untuk itulah diperlukan Kawasan Ekonomi Khusus Bitung dengan core business Industri pengolahan perikanan, industri pengolahan kelapa ,industri farmasi dan logistik yang dipercaya dapat menarik investasi serta membuka lapangan pekerjaan.

Adapun tujuan dari penelitian ini adalah mengukur peranan Kawasan Ekonomi Khusus Bitung dalam Kontribusi khususnya Sektor industri pada Perekonomian Sulawesi Utara. Dalam penelitian ini digunakan Metode Deskriptif Proyeksi untuk melakukan perhitungan berapa kontribusi dari nilai tambah yang akan didapat dengan adanya KEK terhadap indutri kecil, menengah dan besar dengan kajian finansial dari fisibility study awal pembentukan KEK dan Metode Analisa Korelasi untuk membahas seberapa kuat hubungan dan apakah terdapat perbedaan antara adanya KEK dengan tidak adanya KEK terhadap sektor industri untuk perubahan struktur perekonomian provinsi Sulawesi Utara dengan data primer yang diperoleh dari hasil interview dan data sekunder yang diambil dari BPS, dan Kajian Finansial dari Studi Kelayakan Awal pendirian Kawasan Ekonomi Kota Bitung juga metode penelitian pustaka. Dari hasil analisis menunjukkan korelasi industri menengah yang tertinggi untuk ke tiga skenario yang ada (Moderat, Optimis dan Pesimis). Ini berarti bahwa pengembangan industri menengah Kawasan Ekonomi Khusus Bitung memberikan multiplier efek bagi peningkatan pertumbuhan ekonomi di Provinsi Sulawesi Utara dan Kota Bitung, terutama pada peningkatan penyerapan tenaga kerja, peningkatan kontribusi industri menegah pada Struktur Ekonomi pembentuk PDRB.
\end{abstract}

Kata Kunci : Sektor Industri, Struktur Ekonomi, Produk Domestik Regional Bruto, Kawasan Ekonomi Khusus (KEK)

\begin{abstract}
The industrial sector is considered able to boost other sectors in c promoting economic growth of a region that is required for Special Economic Zones with core business in Bitung fishery processing industry, oil processing industry, pharmaceutical industry and logistics that are believed to attract investment and create jobs .The purpose of this study was to measure the role of Special Economic Zones Contributions city of Bitung in particular the industrial sector in North Sulawesi's economy. This study used a descriptive method Projections for calculating the contribution of added value to be gained by the KEK to the industries of small, medium and large with a financial review of Visibility study the early formation of KEK and Correlation Analysis Method to discuss how strong the relationship and whether there is a difference among their KEK in the absence of the industrial sector to change the economic structure of North Sulawesi province with primary data obtained from interviews and secondary data drawn from the CPM and Financial Assessment of Feasibility study Preliminary Economic Zones establishment of Bitung also library research methods. The analysis showed that the highest correlation medium industries for the three scenarios exist (Moderate, Optimistic and Pessimistic). This means that the development of secondary industries Special Economic Zone Bitung provide a multiplier effect for economic growth in the province of North Sulawesi and Bitung, especially on increasing employment, increase the industry's contribution to the Economic Structure-forming medium PDRB.
\end{abstract}

Keywords: Industrial Sector, Economic Structure, Gross Domestic Product, Special Economic Zones (SEZs) 


\section{Latar Belakang Permasalahan}

\section{PENDAHULUAN}

Kemajuan ekonomi suatu bangsa dapat dirasakan dari besarnya kontribusi sektor industri terhadap pertumbuhan ekonominya, bahkan boleh dikatakan dalam sebuah perekonomian sektor industri dianggap sebagai sektor yang mampu menjadi pimpinan dari sektor lain karenaindustri identik dengan nilai tambah, transfer teknologi dan penyerapan tenaga kerja sebagai prasyarat pertumbuhan ekonomi.Tantangan globalisasi dan liberalisasi ekonomi yang paling dirasakan membuat semakin ketatnya persaingan dalam sektor industri hal inimemerlukan peningkatan penanaman modal melalui penyiapan kawasan industri yang memiliki keunggulan karena letaknya yang strategis.Kawasan ini diharapkan mampu mengoptimalkan kegiatan industri serta kegiatan ekonomi lainnya seperti perdagangan, pertanian, perikanan dan pariwisata. Pentingnya membangun sektor industri agar mampu bersaing di era globalisasi sekaligus menjadikannya sebagai motor penggerak perekonomian nasional atau daerah pada masa yang akan datang. Posisi Bitung sangat strategiskarena Kota Bitung hanya terletak $36 \mathrm{~km}$ dari Kota Manado, $8 \mathrm{~km}$ dari Pelabuhan Laut Bitung dan $30 \mathrm{~km}$ dari Bandara Sam Ratulangi apalagi pelabuhan Kota Bitung dekat dengan jalur perdagangan internasional Jepang, Korea Selatan, Amerika, Eropa dibanding pelabuhan-pelabuhan nasional lainnya yang merupakan salah satu simpul laut internasional disamping pelabuhan Kuala Tanjung di Sumatera mengingat saat ini diperkirakan 40\% kegiatan perniagaan dunia melewati wilayah perarian laut dan udara Indonesia. Namun manfaat ekonomi yang diambil negara ini terlampau kecil. Angkutan, asuransi, transit dan transshipment, nilai tambah industri olahan bahkan transporatasi ekspor impor masih tergantung pada Singapura dan negara lainnya. Kawasan Pengembangan Industri mempunyai suatu tujuan terbentuknya kota industri yang langsung berhubungan dengan bandara atau pelabuhan yang mampu memberikan pertumbuhan investasi secara domestik dan menambah nilai tambah bagi investasi asing tetap serta tujuan ekspor industri juga jasa (Scheepers:2012). Hal inilah yang menjadi pertimbangan untuk menetapkan Bitung sebagai Kawasan Ekonomi Khusus di Provinsi Sulawesi Utara, melalui KEK diharapkan mampu mendorong laju perekonomian. Kawasan ekonomi ini didesain berdasarkan Peraturan Pemerintah Nomor 32 Tahun 2014 didukung dengan fasilitas yang jelas dan pajak yang telah ditentukan tentang KEK, pembangunan ini diberikan batas waktu selama 3 tahun hingga tahun 2017. Adapun luas KEK Bitung sampai saat ini seluas $534 \mathrm{Ha}$, diperkirakan Kawasan pengembangan KEK akan menjadi 2.000 Ha termasuk rencana reklamasi pantai seluas $247 \mathrm{Ha}$. Adapun rencana pemanfaatan dari Pengembangan KEK terlihat dari luas pemetaan seperti tercantum dalam Tabel 1 berikut ini 
Tabel 1Rencana Pemanfaatan dari Pengembangan KEK Bitung

$\begin{array}{lll}\text { No Pemetaan Pembangunan Kawasan Ekonomi Khusus (KEK) } & \text { Luas } & \\ \text { 1. Bangunan dan Perbaikan } & 16.40 & \mathrm{Ha} \\ \text { 2. Perencanaan Pelabuhan } & 38.70 & \mathrm{Ha} \\ \text { 3. Pergudangan Logistik } & 38.70 & \mathrm{Ha} \\ \text { 4 Industri Produk Manufaktur } & 39.60 & \mathrm{Ha} \\ \text { 5. Perangkat Keras dan Listrik Khusus } & 319.19 & \mathrm{Ha} \\ \text { 6. Perdagangan dan Logistik } & 38.70 & \mathrm{Ha} \\ \text { 7 Industri Khusus Produk Manufaktur } & 709.00 & \mathrm{Ha} \\ \text { 8. Pelayanan Terpadu (Rumah Sakit, Sekolah, Lokasi } & 225.00 & \mathrm{Ha} \\ \text { Entertainment, Jalan Komersil) } & 295.30 & \mathrm{Ha} \\ \text { 9. Perabotan Rumah Tangga dan Konstruksi } & 173.10 & \mathrm{Ha} \\ \text { 10. Pengolahan Makanan } & 1.988,80 & \mathrm{Ha}\end{array}$

Sumber Koran SINDO 31 Agustus 2016 halaman 1;7

Keberadaan KEK Bitung juga akan membawa dampak besar bagi perkembangan ekonomi daerah SULUT, karena KEK Bitung memiliki kawasan ekonomi pendukung antara lain :

1. Kawasan Pendukung Lolak-Labuhan Uki (Perikanan)

2. Kawasan Pendukung Ratatotok-Lakban (Perikanan dan Wisata Bahari)

3. Kawasan Pendukung Lirung-Melonguane (Perikanan dan Wisata Bahari)

4. Kawasan Pendukung Tahuna-Petta (Perikanan dan Wisata Bahari)

5. Kawasan Pendukung Amurang (Perikanan dan Kelapa)

6. Kawasan Pendukung Tomohon (Florikultur dan Agrowisata)

7. Kawasan Pendukung Likupang (Perikanan dan Wisata Bahari)

Konsekuensi logis dari KEK Bitung adalah pertumbuhan kawasan pendukung yang akan mempercepat dan memperbesar daya serap tenaga kerja, arus investasi lokal, regional, nasional maupun internasional ke Sulut, yang pada akhirnya akan meningkatkan kesejahteraan masyarakat Sulut pada umumnya. Pengembangan KEK dan Kawasan Industri Bitung akan meningkatkan perekonomian di Sulawesi Utara secara signfikan. Pengembangan kawasan strategis Bitung akan meningkatkan keunggulan kompetitif produk ekspor dan meningkatkan pemanfaatan sumber daya lokal, pelayananan, dan kapital. Pengembangan KEK dan KI akan menarik pertumbuhan ekonomi di wilayahnya dan mendorong ekonomi secara merata di seluruh wilayah (Farole 2011) Salah satu upaya untuk meningkatkan taraf perekonomian masyarakat adalah mendorong aktivitas industri. Dengan adanya rencana pengembangan Kawasan Ekonomi Khusus diharapkan masyarakat dapat memanfaatkan kebijakan tersebut untuk peningkatan taraf ekonomi (Tambunan 2001) KEK mempunyai peranan yang penting dalam meningkatkan ekonomi khususnya Sektor Industri, dimana KEK mampu menciptakan peningkatan teknologi, peningkatan produktivitas nasional dan transformasi struktural (Asian Economic Integration Report 2015). Adapun Screepers menyatakan bahwa KEK merupakan salah satu dari banyak alat yang digunakan oleh negara-negara tuan rumah untuk mempromosikan perdagangan dan pembangunan ekonomi sertamampu menarik investasi(Screepers 2012). Lain hal dengan pendapat Rodrik dimana dengan Kawasan Ekonomi Khusus mampu menjadialat yang berguna 
untuk membantu negara-negara untuk berhasil dalam strategi mencapai pertumbuhan ekonomi dengan peningkatan industry yang dapat deengan mudah menumbuhkan Pertumbuhan Ekonomi (Dani Rodrik 2013).

Mengingat pentingnya peranan penting dari Sektor Industri dalam pembangunan nasional. Selain sektor pertanian, kontribusi sektor Industri terhadap pembangunan nasional dari tahun ke tahun menunjukkan kontribusi yang signifikan. Peranan sektor industri dalam pembangunan ekonomi nasional dapat ditelusuri dari kontribusi masing-masing sub sektor terhadap laju pertumbuhan ekonomi nasional. Visi pembangunan industri nasional sebagaimana yang tercantum dalam Peraturan Presiden Nomor 28 Tahun 2008 tentang Kebijakan industri nasional adalah indonesia menjadi negara industritangguh pada tahun 2025. Pola pertumbuhan ekonomi secara sektoral di Provinsi Sulawesi Utara agaknya sejalan dengan kecenderungan proses transformasi struktural yang terjadi di Indonesia meskipun hingga saat ini kontribusi sektor industri dalam menyumbang Produk Domestik Bruto masih lebih rendah dari pada sektor pertanian. Peran strategis sektor industri sebagai mesin pembangunan ekonomi, bukan tanpa alasan, karena sektor industri akan membawa dampak turunan, yakni meningkatnya nilai kapitalisasi modal, kemampuan menyerap tenaga kerja yang besar, serta kemampuan menciptakan nilai tambah (value added creation) dari setiap input atau bahan dasar yang diolah (Eddy Cahyono 2015). Berdasarkan permasalahan diatas, maka timbul suatu pertanyaan berapa besar kontribusi dengan besaran nilai tambah yang dihasilkan setelah adanya Kawasan Ekonomi Khusus dalam perubahan Struktur Industri dalam hal ini Industri Besar, Menengah dan Kecil dalam struktur Perekonomian Sulawesi Utara bila dihitung dengan kajian Finansial yang telah dilakukan pada saat awal pembentukan Kawasan Ekonomi Khusus.

\section{Rumusan Masalah}

Perumusan Masalah Berdasarkan latar belakang di atas, rumusan masalah yang dikemukakan dapat diwujudkan dalam pertanyaan penelitian (research question). Adapun pertanyaan penelitiannya adalah:

1. Apakah terdapat nilai tambah dari ketiga industri (industri kecil, menengah dan besar) yang mampu secara signifikan meningkatkan Produk Domestik Regional Bruto (PDRB)Provinsi Sulawesi Utara dan PDRB Kota Bitung?

2. Industri manakah dari ketiga industri (industri kecil, menengah dan besar) yang memberikan nilai kontribusi terbesar pada struktur ekonomi pembentuk PDRB ?

\section{Tujuan Penelitian}

Penelitian ini bertujuan

1. Untuk mengetahuinilai tambah dari ketiga industri (industri kecil, menengah dan besar) yang mampu secara signifikan meningkatkan Produk Domestik Regional Bruto (PDRB) Provinsi Sulawesi Utara dan PDRB Kota Bitung.

2. Untuk mengetahui industri manakah yang memberikan nilai kontribusi terbesar dalam struktur perekonomian Sulawesi Utara pembentuk PDRB

\section{Manfaat Penelitian}

1. Bagi para pengambil keputusan dan kebijakan (pemerintah) diharapkan kiranya penelitian ini dapat dijadikan sumbangan pikiran sehingga dapat dieksploitir dan dikelolah secara maksimal guna mempercepat pembangunan sektor industri serta struktur perekonomian di Provinsi Sulawesi Utara 
2. Bagi semua pihak terutama para investor dapat mengetahui kondisi kawasan ekonomi khusus Bitung,sehingga perencanaan dan pelaksanaan pembangunan akan lebih terarah ke lokasinya.

3. Sebagai masukan untuk kebijakan penyertaan modal pemerintah nasional dan provinsi serta kabupaten dan kota bagi badan pengelolakawasan ekonomi khusus Bitung

\section{Data dan Sumber Data}

\section{METODE PENELITIAN}

Jenis data yang digunakan dalam penelitian ini adalah data primer yang diperoleh dari hasil interview dan data sekunder berupa data sektor-sektor ekonomi komponen Produk Domestik Regional Bruto (PDRB) Kota Bitung dan Provinsi Sulawesi Utara ADHK 2010 pada tahun 2010-2015.Data lainnya meliputi data keadaan alam, keadaan penduduk, dan keadaan struktur perekonomian dan pertumbuhan ekonomi. Data tersebut berasal dari Badan Pusat Statistik (BPS) Provinsi Sulawesi Utara, BPS Kota Bitung dan Internet. Didalam analisis ini menggunakan tahun dasar 2010 dan dalam menyajikan hasil perkembangan PDRB unggulan Atas Dasar Harga Konstan.Perhitungan ini berguna dalam perencanaan ekonomi, proyeksi dan untuk menilai pertumbuhan ekonomi keseluruhan maupun sektoral.

\section{Metode Pengumpulan Data}

Metode pengumpulan data yang digunakan sehubungan dengan penelitian ini adalah melalui

1. Data Primer yang diambil langsung dari lapangan melalui interview atau wawancara

2. Data Sekunder yang diambil dari BPS, dan kajian finansial dari fisibility study awal pendirian Kawasan Ekonomi Kota Bitung

3. Metode penelitian library research (studi kepustakaan) adalah dengan meneliti dan membaca buku-buku, skripsi, tesis dan jurnal-jurnal yang diterbitkan oleh instansiinstansi yang ada di perpustakaan Fakultas Ekonomi Universitas Sam Ratulangi yang relevan dengan penelitian ini guna mendapatkan landasan teori sebagai bahan pembanding.

\section{Definisi Operasional dan Pengukuran Variabel}

Definisi operasional yang dimaksud berkaitan dengan penjelasan tentang variabelvariabel yang digunakan dalam penelitian ini, dan merupakan upaya untuk menghindari penafsiran yang berbeda. Untuk itu diperlukan penjelasan secara ringkas mengenai variabelvariabel yang digunakan

- Sektor Industri adalah suatu proses yang ditandaidengan penggunaan teknologi didalam proses produksi yang terutama ditujukankepada pengolahan bahan baku, bahan setengah jadi menjadi barang jadi.

1. Industri kecil menurut Undang-Undang No.9/1995 tentang Usaha Kecil adalah aset lebih kecil dari Rp.200 Juta diluar tanah dan bangunan dan menengah, Omzet tahunan lebih kecil dari Rp.1 milyar.

2. Industri Menengah (Inpres 10/1999) Aset Rp.200 Juta - Rp.10 milyar, modal investasi antara Rp. 350 juta sampai 1.500 juta sedangkan nilai Investasi sampai dengan Rp. 5.000.000.000,00.

3. Industri besar, yaitu industri yang investasinya lebih dari Rp.5.000.000.000,00 
- Struktur ekonomi adalah suatu proses yang ditandai adanya transformasi atau peningkatan pendapatan juga beralihnya perekonomian dari sektor primer ke sektor sekunder atau tersier dalam hal ini diukur dalam persen per tahun.

- Produk Domestik Regional Bruto, yaitu: produksi akhir barang dan jasa pada berbagai sektor di Provinsi Sulawesi Utara dan Kota Bitung dalam jangka waktu Lima tahun yang diperoleh dari nilai tambah bruto dari sektor-sektor ekonomi/lapangan usaha yang ada di ukur dalam satuan rupiah pertahun.

\section{Metode Analisis}

Dalam penelitian ini digunakan

1. Metode Deskriptif Proyeksiyakni melakukan perhitungan berapa kontribusi dari nilai tambah yang akan didapat dengan adanya Kawasan Ekonomi Khusus terhadap Industri Besar, Menengah maupun Kecil dengan Kajian Finansial dari Fisibility Study awal pembentukan KEK yang diharapkan mampu memberikan kontribusi terhadap perubahan Struktur perekonomian Sulawesi Utaral

2. Metode Analisa Korelasi yakni studi yang membahas tentang derajat (seberapa kuat) hubungan antara dua variable atau lebih. Membuat analisa apakah ada hubungan apakah terdapat perbedaan antara adanya KEK dengan tidak adanya KEK terhadap sektor industri untuk perubahan struktur perekonomian provinsi Sulawesi Utara.

\section{HASIL DAN PEMBAHASAN}

\section{Analisa Kontribusi KEK terhadap Struktur perekonomian Sulawesi Utara}

Implementasi awal dalam pengembangan sektor industri di Sulawesi Utara adalah ditetapkannya Kecamatan Matuari Kota Bitung Provinsi Sulawesi Utara sebagai pusat kegiatan perindustrian dan sebagai pusat layanan industry berbasis logistik dan distribusi dengan ditetapkan melalui Peraturan Pemerintah Republik Indonesia Nomor 32 tahun 2014 tentang Kawasan Ekonomi Kota Bitung, dimana disebutkan wilayah Bitung memiliki potensi dan keunggulan secara geoekonomi dan geostrategic untuk dijadikan sebagai Kawasan Ekonomi Khusus oleh pemerintah. Lokasi tersebut juga sangat strategis untuuk industri pengolahan perikanan dimana Sulawesi Utara adalah salah satu penghasil ikan terbesar di Indonesia yang mampu memberi kontribusi yang signifikan terhadap Produk Domestik Regional Bruto (PDRB) dari Sulawesi Utara. Nilai investasi pembangunan kawasan 1,7 triliun, atau diperkirakan menarik investasi Rp. 32,89 triliun hingga 2025 dan akan menyerap tenaga kerja 34.000 orang. KEK Bitung juga akan memiliki zonasi antara lain; industri kelapa 65,4 ha, industri perikanan 50 ha, industri farmasi 105,5 ha, industri lainnya 41,1 ha, logistik 25,8 ha. Pengembangan KEK Bitung maka akan lebih mudah untuk mendukung upaya menggerakkan roda ekonomi di Sulawesi Utara, sehingga dapat memberikan kontribusi yang nyata dan upaya mengurangi angka kemiskinan dan pengangguran, dan meningkatkan kesejahteraan masyarakat di Provinsi Sulawesi UtaraDalam usaha mulainya pembangunan Industri KEK di Bitung tentunya harus didukung dengan dipercepatnya pembangunan infrastruktur transportasi di wilayah Sulawesi Utara.

Pengembangan Pelabuhan Bitung sebagai International Hub Sea Port (IHP) yang mampu meningkatkan ekspor dan impor juga mampu menampung kapal bermuatan lima ribu kontainer yang hendak mengekspor barang dari Bitung ke Luar negeri, ataupun kapal asing yang singgah di Pelabuhan Bitung, dengan menjadi tempat persinggahan sehingga komoditas ataupun hasilhasil yang ada di Bitung akan mampu terjual karena Pelabuhan Bitung saat ini hanya mampu 
menampung kapal yang bermuatan tiga ribu kontainer. Dengan IHP mampu menjadikan Kota Bitung menjadi Pelabuhan petikemas bertaraf internasional sehingga diharapkan mampu menjadi simpul konektivitas perdagangan wilayah Indonesia timur.

\section{Analisa Proyeksi}

Perlunya analisa proyeksi untuk dapat memberikan suatu kajian studi kelayakan finansial, isi dari studi ini memberikan informasi tentang analisis kebutuhan biaya pengembangan KEK, pendapatan dari pengembangan KEK dan kelayakan Usaha (aspek financial).Namun dalam penelitian ini lebih disorot analisa Distribusi Kavling laku (sewa) yang telah dilakukan penelitian sebelumnya memaui feasibility study (analisa kelayakan keuangan) yang telah dilakukan pada awal proyek Kawasan Ekonomi Khusus Bitung akan dimulai. Penerimaan atau pendapatan operasi KEK diperoleh dari satu sumber utama yaitu pendapatan hasil sewa kavling. Agar lebih realistis maka digunakan tiga skenario yaitu optimis, moderat (case based) dan pesimis dengan d.ata sebagai berikut: (Study Kelayakan Kelembagaan ekonomi dan Finansial 2011). Adapun skim pemasaran lahan terdiri dari informasi tentang opsi sewa dan beli kavling yang ada di KEK. komposisi kavling yang ada di KEK direncanakan sebanyak 455 kavling dengan perincian untuk kavling industri besar sebanyak 20 kavling (4,4\%), industri menengah 92 kavling (26,8\%)dan industri kecil sebanyak 343 kavling $(75,4 \%)$. Untuk scenario optimis kavling diasumsikan laku $100 \%$ pada tahun ke-17, untuk scenario base case (moderat), diasumsikan laku pada tahun ke 20 dan untuk scenario pesimis, kavling diasumsikan laku hanya pada 15 (hanya $75 \%$ ).

\section{Analisa Korelasi}

variabel.Koefisien korelasi populasi $\rho$ (rho) adalah ukuran kekuatan hubungan linier antara dua variabel dalam populasi sedangkan koefisien korelasi sampel $r$ adalah estimasi dari $\rho$ dan digunakan untuk mengukur kekuatan hubungan linier dalam sampel observasi. Untuk selanjutnya r disebut Koefisien Korelasi Pearson Product Moment

\section{Korelasi Pearson (Product Moment)}

Korelasi pearson sering juga disebut sebagai korelasi produk-momen atau korelasi saja. Korelasi pearson termasuk ke dalam statistika parametrik. Besarnya koefisien menggambarkan seberapa erat hubungan linear antara dua variabel, bukan hubungan sebab akibat. Variabel yang terlibat dua-duanya bertipe numerik (interval atau rasio), dan menyebar normal jika ingin pengujian terhadapnya sah. Berikut ini pedoman menentukan kuat tidaknya korelasi antara dua variabel menurut Walpole :

\begin{tabular}{|c|c|}
\hline Intcrval Korfisicn & Tingkat Hubungan \\
\hline $0.00-0.199$ & Salligat iendath \\
\hline 1) $>0-11 \div 09$ & Ecosdah \\
\hline $0.40-0.599$ & Cukue \\
\hline $\begin{array}{ll}0.00 & 0.799\end{array}$ & Kunt \\
\hline $0.80-1.000$ & Sankal Kua. \\
\hline
\end{tabular}

Menurut Sarwono (2006) Batas-batas nilai koefisien korelasi diinterpretasikan sebagai berikut: 


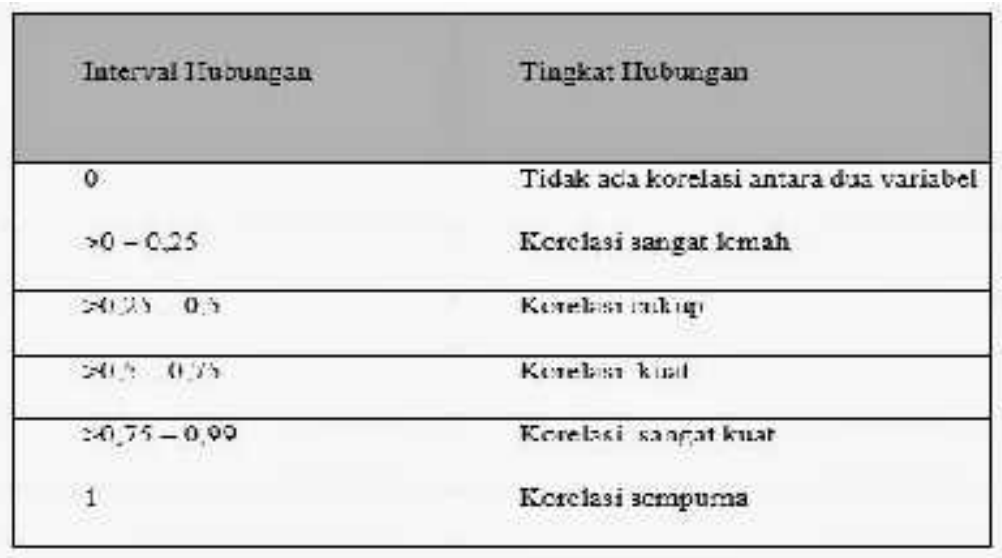

Hasil dari analisis korelasi menunjukkan kekuatan atau kelemahan dari suatu hubungan. Nilai koefisien korelasi ini akan berada pada kisaran -1 sampai dengan +1 . Analisa Korelasi dalam penelitian ini dilihat dari 2(dua) pemandangan, yakni:

1. Analisa Korelasi Kawasan Ekonomi Khusus Bitung dikorelasikan dengan Industri yang berada di Kawasan Provinsi Sulawesi Utara

2. Analisa Korelasi Kawasan Ekonomi Khusus Bitung dikorelasikan dengan Industri yang berada di Kawasan Provinsi Sulawesi Utara

\section{Nilai Tambah (Value Added) PDRB Provinsi Sulawesi Utara khususnya Sektor Industri berdasarkan 3 (tiga Skenario)}

Analisa Korelasi Penelitian diatas dapat disimpulkandalam Tabel 1 dan Gambar 1 di bawah ini

Tabel 1 Analisa Korelasi Nilai Tambah (Value Added) PDRB Provinsi Sulawesi Utara dan Kota Bitung terhadap Sektor Industri

\begin{tabular}{|c|c|c|c|c|c|c|c|c|c|c|c|c|}
\hline \multirow[b]{2}{*}{ KETERANGAN } & \multicolumn{4}{|c|}{ Pesimis } & \multicolumn{4}{|c|}{ Moderat } & \multicolumn{4}{|c|}{ Optimis } \\
\hline & $\begin{array}{c}\text { Industri } \\
\text { Besar }\end{array}$ & $\begin{array}{c}\text { Industri } \\
\text { Menengah }\end{array}$ & $\begin{array}{c}\text { Industri } \\
\text { Kecil }\end{array}$ & Total & $\begin{array}{c}\text { Industri } \\
\text { Besar }\end{array}$ & $\begin{array}{c}\text { Industri } \\
\text { Menengah }\end{array}$ & $\begin{array}{c}\text { Industri } \\
\text { Kecil }\end{array}$ & Total & $\begin{array}{c}\text { Industri } \\
\text { Besar }\end{array}$ & $\begin{array}{c}\text { Industri } \\
\text { Menengah }\end{array}$ & $\begin{array}{c}\text { Industri } \\
\text { Kecil }\end{array}$ & Total \\
\hline $\begin{array}{c}r \\
\text { Provinsi }\end{array}$ & $80,12 \%$ & $80,18 \%$ & $80,11 \%$ & $80,13 \%$ & $80,14 \%$ & $80,25 \%$ & $80,12 \%$ & $80,17 \%$ & $80,14 \%$ & $80,21 \%$ & $80,11 \%$ & $80,16 \%$ \\
\hline r Bitung & $80,18 \%$ & $80,36 \%$ & $80,14 \%$ & $80,23 \%$ & $80,25 \%$ & $80,57 \%$ & $80,18 \%$ & $80,34 \%$ & $80,24 \%$ & $80,46 \%$ & $80,16 \%$ & $80,29 \%$ \\
\hline
\end{tabular}

Gambar 1 Analisa KorelasiNilai Tambah PDRB Provinsi Sulawesi Utara dan PDRB Kota Bitung terhadap Sektor Industri 


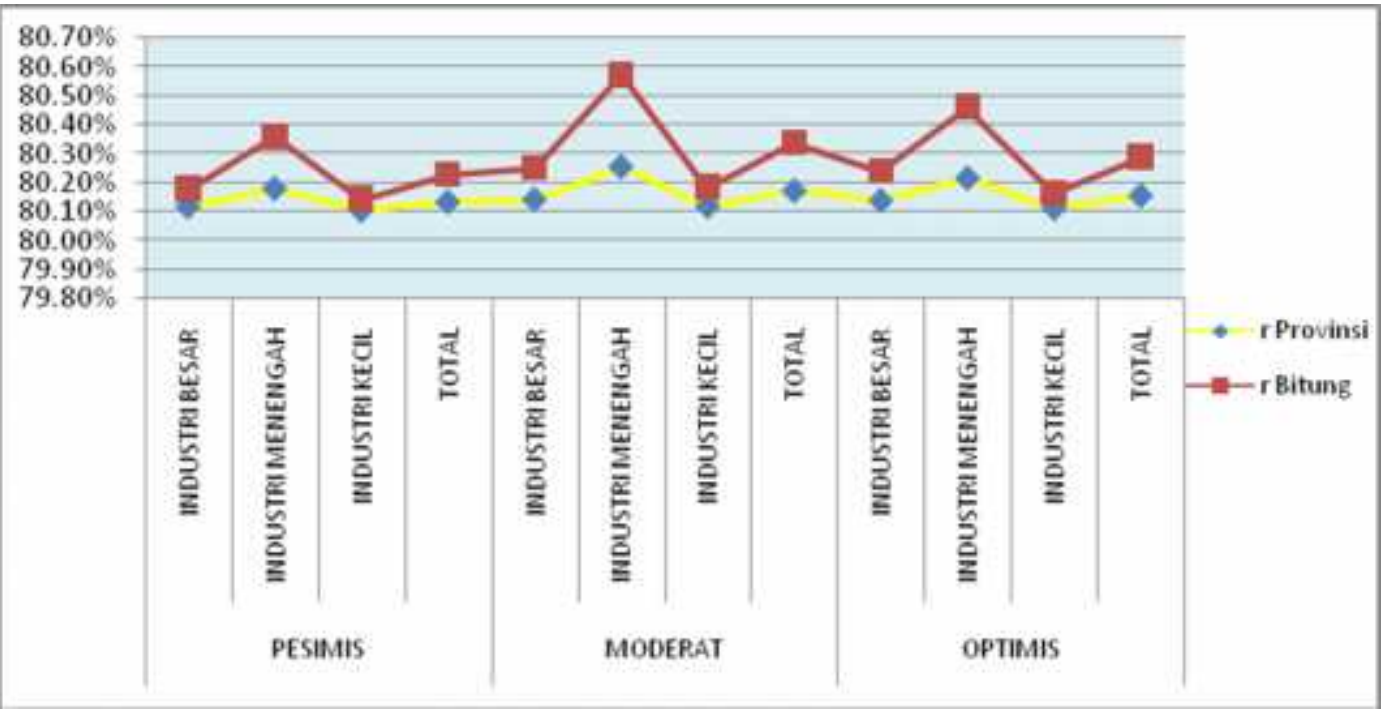

\section{Analisa Kawasan Ekonomi Khusus (KEK) di Provinsi Sulawesi Utara}

Hasil penelitian menunjukkan bahwa analisa kontribusi melalui analisa korelasi didapati bahwanilai tambah Produk Domestik Regional Bruto (PDRB) menurut 3 (tiga) skenario adalah:

1. Industri menengah memiliki nilai tambah terbesar dari ke 3 (tiga) skenario sehingga perusahaan yang berada di Industri menengah di Kawasan ekonomi Khusus menjadi perhatian utama bagi Provinsi Sulawesi Utara

2. Industri menengah juga memiliki nilai tambah terbesar pada ke 3 (tiga) skenario, juga guna peningkatan PDRB di Kota Bitung. Ini berarti peran Industri Menengah yang akan beroperasi di Kawasan Ekonomi Khusus Bitung menjadi target utama bagi Kota Bitung.

Analisis Kontribusi melalui analisa korelasi dari Industri besar, industri menengah dan industri kecil di Kawasan Ekonomi Khusus Bitung menjadi bahan untuk Provinsi Sulawesi Utara khususnya Kota Bitung ternyata korelasi industri menengah yang tertinggi untuk ke 3 (tiga) skenario yang ada. Ini berarti bahwa pengembangan industri menengah Kawasan Ekonomi Khusus Bitung memberikan multiplier effect bagi peningkatan pertumbuhan ekonomi di Provinsi Sulawesi Utara dan Kota Bitung, terutama pada peningkatan penyerapan tenaga kerja, peningkatan kontribusi industri menegah pada Struktur Ekonomi pembentuk PDR. Keterlibatan Usaha Mikro, Kecil, dan Menengah (UMKM) nyata disebutkan dalam Undang-undang nomor 39 Tahun 2009 tentang Kawasan Ekonomi Khusus Pasal 3: "Di dalam setiap KEK disediakan lokasi untuk usaha mikro kecil, menengah (UMKM) dan Koperasi, baik selaku Pelaku Usaha maupun sebagai pendukung kegiatan perusahaan yang berada di dalam KEK". Hal inilah yang dapat menampik bahwa kehadiran KEK dengan berbagai insentif yang diberikan akan berpotensi mematikan UMKM lokal yang ada di sekitarnyajika tidak ada integrasi antara KEK dan UMKM lokal dalam hubungan hulu-hilir Untuk mendukung penelitian ini didapatkan pula data Rekapitulasi Usaha Mikro, Kecil, dan Menengah (UMKM) Kota Bitung tahun 2015 seperti terlihat dalam Tabel 4.50 dibawah ini 
Tabel 2

Rekapitulasi Usaha Mikro, Kecil, dan Menengah (UMKM)

Kota Bitung Tahun 2015

\begin{tabular}{|c|c|c|c|c|c|}
\hline \multirow{2}{*}{ No } & \multirow{2}{*}{ Uraian } & \multicolumn{2}{|c|}{ Kriteria dari UU Nomor 20 tahun 2008} & \multirow{2}{*}{$\begin{array}{l}\text { Jumlah } \\
\text { Usaha }\end{array}$} & \multirow{2}{*}{$\begin{array}{l}\text { Jumlah } \\
\text { Tenaga }\end{array}$} \\
\hline & & Asset & Omzet & & \\
\hline 1 & MIKRO & Maks. 50 Juta & Maks 300 Juta & 2,845 & 3,836 \\
\hline 2 & KECIL & $>50$ Juta - 500 Juta & $>300$ Juta - 2,5 Miliar & 543 & 4,897 \\
\hline 3 & MENENGAH & $>500$ Juta - 10 Miliar & $>2,5$ Miliar - 50 Miliar & 58 & 7,315 \\
\hline & \multicolumn{3}{|c|}{ TOTAL } & 3,446 & 16,048 \\
\hline
\end{tabular}

Sumber: Dinas Koperasi dan UKM Kota Bitung 2015

Bila dilihat dari Industri menengah yang berada di Provinsi Sulawesi Utara maka akan terlihat jelas dalam Tabel 4.51 dengan jumlah 985 unit usaha dengan didominasi oleh industri pangan sebanyak 426 unit usaha (43\%) disusul industri kimia dan bahan bangunan sebanyak 241 unit usaha $(24 \%)$.

\section{Kesimpulan}

\section{KESIMPULAN DAN SARAN}

Berdasarkan hasil penelitian, maka dapat disimpulkan :

Analisis Kontribusi melalui analisa korelasi didapati bahwa nilai tambah Produk Domestik Regional Bruto (PDRB) menurut 3 (tiga) skenario adalah:

1. Industri menengah memiliki nilai tambah terbesar dari ke 3 (tiga) skenario sehingga perusahaan yang berada di Industri menengah di Kawasan ekonomi Khusus menjadi perhatian utama bagi Provinsi Sulawesi Utara

2. Industri menengah juga memiliki nilai tambah terbesar pada ke 3 (tiga) skenario, juga guna peningkatan PDRB di Kota Bitung. Ini berarti peran Industri Menengah yang akan beroperasi di Kawasan Ekonomi Khusus Bitung menjadi target utama bagi Kota Bitung AnalisisKontribusi melalui analisa korelasi dari Industri besar, industri menengah dan industri kecil di Kawasan Ekonomi Khusus Bitung menjadi bahan untuk Provinsi Sulawesi Utara khususnya Kota Bitung ternyata industri menengah yang tertinggi untuk ke 3 (tiga) skenario yang ada. Ini berarti bahwa pengembangan industri menengah Kawasan Ekonomi Khusus Bitung memberikan multiplier effectbagi peningkatan pertumbuhan ekonomi di Provinsi Sulawesi Utara dan Kota Bitung, terutama pada peningkatan penyerapan tenaga kerja, peningkatan kontribusi industri menegah pada Struktur Ekonomi pembentuk PDRB

\section{Saran}

Berdasarkan hasil penelitian ini, peneliti mencoba memberikan saran sebagai berikut :

1. Bagi Pemerintah Provinsi Sulawesi Utara

- Pemerintah Provinsi Sulawesi Utara lebih menfasilitasi dan pengembangan industri menengah yang mampu meningkatkan PDRB maupun pertumbuhan ekonomi Kota Bitung dan Provinsi Sulawesi Utara

- Pemerintah Provinsi Sulawesi Utara perlu lebih berusaha untuk segera menfasilitasi pembangunan infrastruktur transportasi di wilayah Provinsi Sulawesi

- Kondisi Infrastruktur jalan, sarana dan prasarana transportasi masih terbatas serta ketersediaan Energi Listrik masih terkendala (krisis energi) 
- Lebih mengoptimalkan pemanfaatan Bitung sebagai pelabuhan ekspor wilayah timur yang masih menggunakan pelabuhan Surabaya dan Jakarta yang lebih jauh dan lebih mahal

- Sebagai masukan untuk kebijakan penyertaan modal pemerintah nasional dan provinsi serta kabupaten dan kota bagi badan pengelola kawasan ekonomi khusus Bitung

2. Bagi para investor lebih dapat menfokuskan perhatiannya pada pengembanganindustri menengah karena diketahui kontribusi nilai tambah kawasan ekonomi khusus Bitung dengan pendekatan tiga skenario paling memberikan multiplier effect bagi peningkatan pertumbuhan ekonomi di Provinsi Sulawesi Utara dan Kota Bitung, terutama pada peningkatan penyerapan tenaga kerja, peningkatan kontribusi industri menegah pada struktur ekonomi pembentuk PDRB

- Pemerintah secara nasional, provinsi dan kota juga badan pengelola kawasan ekonomi khusus Bitung lebih dapat menfokuskan perhatiannya pada pengembangan industri menengah untuk kebijakan penyertaan modal.

\section{DAFTAR PUSTAKA}

Adiguna Norman Fajar (2016) Analisis Kebijakan Pemerintah Cina dalam Penetapan Kashgar di Xinjiang sebagai Special Economic Zone (SEZ) pada Tahun 2010 FISIP Universitas Gadjah Mada Yogyakarta

Al Sakka Fadi Abdulmoein 2014 Human Capital Development in the Special Economic Zone : The Case of Dubai University of Salford, Salford, UK

Anugrahaini Dewi Nur 2015 Perkembangan Kawasan Ekonomi Khusus (KEK) Batam dalam Pemberlakuan Free Trade Zone (FTZ)

Arnisson Andre Ortega,,Johanna Marie Astrid E. Acielo, Maria Celeste H. Hermida 2015 Mega-regions in the Philippines: Accounting for special economic zones and global-local dynamics

Asian Economic Integration Report 2015 (2015). Special Chapter: How Can Special Economic Zones Catalyze Economic Development

Badan Perijinan dan Penanaman Modal Kota Bitung 2015 Jumlah Perusahaan dan Nilai Investasi PMA dan PMDN berdasarkan Sektor Usaha

Badan Pusat Statistik, 2015. Produk Domestik Regional Bruto Provinsi Sulawesi Utara. Tahun 2010-2015

Badan Pusat Statistik, 2015. Produk Domestik Regional Bruto Kota Bitung. Tahun 2010-2015

Bethany Anne Zimmerman (2013) Sustainable Operation of Special Economic Zones in India: A Comparative Study of Maharashtra and Goa

Cahyono Eddy 2015 Industrialisasi dan Transformasi Ekonomi, Harian Ekonomi Neraca

Coenrad Muller Scheepers 2012 A Case Study for Special Economic Zones in South Africa as A Means of Attracting Foreign Direct Investment, University of Pretoria

Etienne L. Nel \& Christian M. Rogerson 2013 Special Economic Zones in South Africa: Reflections from International Debates Nel, E.L. \& Rogerson, C.M. Urban Forum

Farole Thomas (2011) Special Economic Zone :Progress, Emerging Challenges, and Future Directions International Trade Department World bank

Honita Cowaloosur $2014 \mathrm{Re}$ - Inscribing Dependency: The Political Economy of Mauritius Jin Fei Economic and Trade Cooperation Zone Co. Ltd. School of International Relations of the University of St Andrews 
Herlevi April A. (2016). What's So Special about Special Economic Zones? China's National and Provincial-Level Development Zones

Jhingan, M.L. (1997), Ekonomi Pembangunan Dan Perencanaan, PT. Raja Grafindo Persada.

Kamran Habbibiyan and Mohammad Feizi (2013) Evaluation of effective factors on personnel individual resistance in Bandar Imam Special Economic Zone

Konstantinos J. Hazakis (2012) Key Conditions for the Effectiveness of Special Economic Zones in Regional Development: Opportunities and Challenges for the Thrace Region Greece Horizon

Kuncoro, Mudrajad. 2004. Otonomi dan Pembangunan Daerah: Reformasi,Perencanaan, Strategi dan Peluang. Penerbit Erlangga: Jakarta

Long Teng (2016) How Special Economic Zones Influence Economic Development in East Asia: A Comparative Study on the Impact of Zouping National Economic and Technological Development Zone and Daegu - Gyeongbuk Free Economic Zone on The Local Economic Development During the Area of Financialization University of Minnesota, Twin Cities, with a Minor in Management at the Carlson School of Management.

Maramis Joubert B, Masinambouw Vecky, Walewangko Een (2011) Study Kelayakan Kelembagaan Ekonomi dan Finansia Universitas Sam Ratulangi

Moberg Lotta (2015) The political economy of special economic zones, Journal of Institutional Economics / Volume 11 / Issue 01 / March 2015, pp 167 - 190

Montague J. Lord and Pawat Tangtrongjita (2014) Special Border Economic Zone (SBEZ) in th e Indonesia-Malaysia-Thailand Growth Triangle (IMT-GT)

Peraturan Pemerintah Republik Indonesia Nomor 32 Tahun 2015, Kawasan Ekonomi Khusus Bitung

Peraturan Presiden Nomor 28 Tahun 2008, Kebijakan Industri Nasional

Polloshka Bleta 2015, Fostering Economic Growth: The Establishment of the Free Economic Zone in Gjakova Rochester Institute of Technology RIT Scholar Works

Provinsi Sulawesi Utara (2015) Seri Analisis Pembangunan Wilayah Provinsi Sulawesi Utara 2015

Rodrik Dani 2013, Structural Change, Fundamentals and Growth: an Overview

Sindo Koran, 31 Agustus 2016 Halaman 1;7 Rencana Pemanfaatan dari Pengembangan KEK Bitung

Surat Keputusan Menteri Perindustrian Nomor 19 /M/I/1986 Sistem Klasifikasi Industri serta pemberian Nomor Kodenya yang berada dibawah masing-masing Direktorat Jenderal dalam Lingkungan Departemen Perindustrian

Sukirno, Sadono 2006. Makroekonomi: Teori Pengantar, Penerbit PT. Raja Grafindo Persada, Jakarta

Sukirno, Sadono.2007, Makro Ekonomi Modern . Jakarta : PT.Raja Grafindo Persada

Sukirno,Sadono. (1998), Beberapa Aspek dalam Pembangunan Daerah, Jakarta.

Suparmoko,M. (2006), Ekonomo Publik Untuk Keuangan Dan PembangunanDaerah, Andi, Yogyakarta.

Tambunan Tulus, (2001). Perekonomian Indonesia Beberapa masalah Penting, Ghalia Indonesia, Jakarta.

Tarigan Budi (2012) Pengembangan Kawasan Ekonomi Khusus, Universitas Sam Ratulangi

Tarigan R (2009) Ekonomi Regional, Teori dan Aplikasi, PT.Bumi Aksara Jakarta 
Timur Gareev (2013) The special economic zone in the Kaliningrad region:development tool or institutional trap?, Baltic Journal of Economics,

Todaro Michael P., 2000, Economic Development, Seventh Edition, Ney York University, Addison Mesley

Undang-undang Republik Indonesia Nomor 9 Tahun 1995, Usaha Kecil, Presiden Republik Indonesia

Undang-undang Republik Indonesia Nomor 20 Tahun 2008, Usaha Mikro, Kecil dan Menengah, Presiden Republik Indonesia

Undang-undang Republik Indonesia Nomor 39 Tahun 2009, Kawasan Ekonomi Khusus, Presiden Republik Indonesia

Undang-undang Republik Indonesia Nomor 3 Tahun 2014, Perindustrian, Presiden Republik Indonesia

Wenze Yue, Pelilei Fan, Yehua Dennis Wei, Jiaguo Qi (2014) Economic development urban expansionand sustainable development in Shanghai

Yong Geng, Zuoxi Liu, Bing Xue, Huijuan Dong, Tsuyoshi Fujita, Anthony Chiu (2014) Emergy-based assessment on industrial symbiosis: a case of Shenyang Economic and Technological Development Zone Environmental Science and Polution Research

Yoze Rizal Damuri, David Christian, Raymond Altje (2015) Kawasan ekonomi khusus dan strategis Indonesia : tinjauan atas peluang dan permasalahan Jakarta : Centre for Strategic and International Studies 